\title{
Anodization of Aluminium using a fast two-step process
}

\author{
MURUGAIYA SRIDAR ILANGO, AMRUTA MUTALIKDESAI and SHEELA K RAMASESHA* \\ Divecha Centre for Climate Change, Indian Institute of Science, Bangalore 560 012, India \\ e-mail: sheela@caos.iisc.ernet.in
}

MS received 10 August 2015; revised 26 October 2015; accepted 10 November 2015

\begin{abstract}
Ultra-fast two-step anodization method is developed for obtaining ordered nano-pores on aluminium (Al) foil. First anodization was carried out for $10 \mathrm{~min}$, followed by $3 \mathrm{~min}$ of second anodization at high voltage $(150 \mathrm{~V})$ compared to previous reports of anodization times of $12 \mathrm{~h}(40-60 \mathrm{~V})$. The pore dimensions on anodized alumina are $180 \mathrm{~nm}$ for pore diameter and $130 \mathrm{~nm}$ for inter-pore distance. It was evident that by increasing the anodization voltage to $150 \mathrm{~V}$, the diameter of the pores formed was above $150 \mathrm{~nm}$. The electrolyte and its temperature affect the shape and size of the pore formation. At lower anodization temperature, controlled pore formation was observed. The anodized samples were characterized using the field emission scanning electron microscope (FE-SEM) to determine the pore diameter and inter-pore distance. Using UVVisible spectroscopy, the reflectance spectra of anodized samples were measured. The alumina $\left(\mathrm{Al}_{2} \mathrm{O}_{3}\right)$ peaks were identified by $\mathrm{x}$-ray diffraction (XRD) technique. The x-ray photo electron spectroscopy (XPS) analysis confirmed the $\mathrm{Al} 2 \mathrm{p}$ peak at $73.1 \mathrm{eV}$ along with the oxygen $\mathrm{O} 1 \mathrm{~s}$ at $530.9 \mathrm{eV}$ and carbon traces $\mathrm{C} 1 \mathrm{~s}$ at $283.6 \mathrm{eV}$.
\end{abstract}

Keywords. Anodization; phosphoric acid; anodization time; anodized aluminium oxide; aluminium.

\section{Introduction}

Anodization is the process of creating nanopores, on the surface of aluminium ( $\mathrm{Al}$ ) to form an anodic alumin ium oxide (AAO), using the method of electrochemical fabrication. ${ }^{1,2}$ Anodization parameters control the arrangement of nanopore formation. The pores formed are parallel to each other and perpendicular to the surface of the foil. ${ }^{3,4}$ The hexagonal structures in AAO are dependent on the type and concentration of the electrolyte, temperature, applied voltage and duration of anodization..$^{5-7}$ The AAO layer has a large band gap, good dielectric constant, mechanical strength and corrosion resistance. ${ }^{8-11}$

AAO templates are obtained using electrolytes such as oxalic, chromic, phosphoric or sulphuric acid. ${ }^{12-16}$ The anodization voltage can be varied according to the type of electrolyte used. Sulphuric acid 0.3 M (25 V), phosphoric acid 0.1 M (150-195 V) and oxalic acid 0.3 $\mathrm{M}(40 \mathrm{~V})$ for 12 hours of anodization time can form 63,500 and $100 \mathrm{~nm}$ interpore distance respectively. ${ }^{17-20}$ Organic electrolytes such as malonic and tartaric acid are also used to form self-ordered porous alumina films. ${ }^{21}$ The temperature variations in the electrolyte affect the porosity of the anodized sample. The rate of formation of pores increases with increase in temperature. ${ }^{22}$

*For correspondence
Different methods of anodization are single step, pre-patterned and two-step anodization. Single step anodization is carried out using sulphuric, oxalic and phosphoric acid to obtain nanoporic oxide layer which has non-uniform pores and inter-pore distance. ${ }^{23}$ Prepatterned anodization is a process of inscribing the patterns on the $\mathrm{Al}$ surface using techniques such as UV exposure, e-beam lithography. Later, anodization is carried out using oxalic acid to grow AAO templates. $^{24}$ Two-step anodization recently resulted in uniform self-organised nanopores on Al substrates. In two-step anodization, homogeneous or heterogeneous electrolytes are used to anodize the sample separately. Typically the first anodization takes a longer period $(12 \mathrm{~h}$ at $195 \mathrm{~V})$ for template formation; ${ }^{25}$ this template acts as the pattern for the second anodization. In one of the reports, sulphuric acid was used as the electrolyte for the first anodization to form pits on $\mathrm{Al}$ substrate, while in second anodization these pits act as the pattern for nanopore formation. ${ }^{26}$ Nanoporous alumina is used in the development of thermoelectric devices using metamaterials and for energy harvesting. Anodized magnetic nanohole arrays are used in biological and biomedical applications. ${ }^{27}$

In this paper, we report an anodization process where the total anodization time has been reduced from 12 $\mathrm{h}$ at $195 \mathrm{~V}^{25}$ of previous reports to $15 \mathrm{~min}$ at $150 \mathrm{~V}$ and the self-ordering of the pores formed are in good 
agreement with the literature. The effects of anodizing parameters on the nano-pore formation are analysed. Two-step anodization process is followed to fabricate AAO templates with $180 \mathrm{~nm}$ pore diameter. The combination of oxalic acid in first anodization and phosphoric acid in second anodization is chosen with optimized anodization parameters for uniform pore formation.

\section{Experimental}

A high purity aluminium foil of $0.5 \mathrm{~mm}$ thickness (Merck-99.99\%) was cut into strips of dimension $10 \mathrm{x}$ $30 \mathrm{~mm}^{2}$. These strips were ultrasonicated in de-ionized water and acetone for $5 \mathrm{~min}$ in each solution. The strips of $\mathrm{Al}$ were blow dried, annealed at $300^{\circ} \mathrm{C}$ for $10 \mathrm{~min}$ in the air ambient. The annealed samples were degreased using acetone and de-ionised water for $10 \mathrm{~min}$ separately. After degreasing, the sample was etched using $0.75 \mathrm{M}$ sodium hydroxide by dipping the samples in the solution for $4 \mathrm{~min}$. To reduce the surface irregularities, the samples were electro-polished in the solution containing 1:4 v/v mixture of perchloric acid $\left(\mathrm{HClO}_{4}\right)$ and ethanol $\left(\mathrm{C}_{2} \mathrm{H}_{5} \mathrm{OH}\right)$ at $7^{\circ} \mathrm{C}$ with a constant voltage of $15 \mathrm{~V}$ for $3 \mathrm{~min}$. After electro-polishing, the Al strips were washed with de-ionized water and acetone. The porous AAO layer was fabricated by the two-step anodization process.

In the first step of anodization, oxalic acid was used as an electrolyte where the weak spots (pattern) were formed. The ultra-fast second anodization was carried out using orthophosphoric acid $\left(\mathrm{H}_{3} \mathrm{PO}_{4}\right)$ electrolyte. In a hundred millilitre beaker, $80 \mathrm{~mL}$ of $0.3 \mathrm{M}$ oxalic acid was prepared and carefully placed in polystyrene container filled with a mixture of grated ice and rock salt. The purpose of rock salt with the ice is to maintain the temperature below $273 \mathrm{~K}$. By using a thermometer the temperature of the electrolyte was constantly verified. When the temperature of the solution reaches $280 \mathrm{~K}$, the platinum coil which acts as the cathode was dipped in to the solution. Simultaneously, the electro-polished Al strip connected to the anode of DC power supply was inserted. Anodization was carried out for $10 \mathrm{~min}$ at a constant voltage of $40 \mathrm{~V}$. Then the sample was rinsed in de-ionized water and dipped in an etching mixture of $3.5 \mathrm{wt} \% \mathrm{H}_{3} \mathrm{PO}_{4}$ and $4.5 \mathrm{wt} \%$ of chromic acid $\left(\mathrm{H}_{2} \mathrm{CrO}_{4}\right)$ at $353 \mathrm{~K}$ for $5 \mathrm{~min}$. The above step removed the oxide layer formed during first anodization, leaving behind the weak point for the second anodization. The second anodization was carried out with a similar apparatus setup and $1 \% \mathrm{H}_{3} \mathrm{PO}_{4}$ was used as the electrolyte at a constant voltage of $150 \mathrm{~V}$ at a temperature of $283 \mathrm{~K}$ for 2 min.
Pores in anodic aluminium oxide layer were characterized and analysed using FE-SEM images (Ultra 55, field emission scanning electron microscope (Carl Zeiss)). Physical properties such as pore diameter and interpore distance were measured and averaged considering the pores present in the FE-SEM images. The interconnected, incomplete pores were not taken into account. Reflectance spectra were taken from UVVisible spectrometer (analytic jena SPECORD S-600) for analysing the differences between the absorption of anodized samples with different pore size. XPS (ultra AXIS) analysed the intensity peaks and orbital values. XRD (Bruker D8 advance) was used to identify the peaks of alumina after anodization.

\section{Results and Discussion}

Anodization process takes place with the oxygen ions present in the electrolyte which reacts with the surface of the $\mathrm{Al}$ to remove the $\mathrm{Al}^{3+}$ ions. The motivation of this work is to lower the time taken for the anodization process and to analyse the AAO pore formation using different acids such as oxalic and phosphoric acid. Time taken for the first and second anodization was 10 and 3 minutes, respectively. In the context of fabricating AAO pores with diameter and wall thickness of $200 \mathrm{~nm}$, twostep anodization using oxalic acid and phosphoric acid was attempted. The initial step is to create a template for the oxide growth along with the pore formation. Oxalic acid anodization was carried out at a potential of $40 \mathrm{~V}$, keeping the temperature constant at $280 \mathrm{~K}$.

\subsection{Step one of anodization using oxalic acid}

The arrangement of pores and structural features of the oxide layer formed after anodization with different concentrations of oxalic acid are characterized using FE-SEM images. Pore diameter is the diameter of the circular holes formed on the alumina and wall thickness is the distance between one edge of the pore to the other edge of neighbouring pore. Table 1 shows the variations of pore diameter and wall thickness for increasing

Table 1. Anodization using oxalic acid at a constant time, temperature and voltage of $10 \mathrm{~min}, 280 \mathrm{~K}$ and $40 \mathrm{~V}$ respectively.

\begin{tabular}{lccc}
\hline $\begin{array}{l}\text { Sample } \\
\text { no. }\end{array}$ & $\begin{array}{c}\text { Weight } \\
(\%)\end{array}$ & $\begin{array}{c}\text { Pore diameter } \\
(\mathrm{nm})\end{array}$ & $\begin{array}{c}\text { Wall thickness } \\
(\mathrm{nm})\end{array}$ \\
\hline 1 & 3.7821 & 96 & 50 \\
2 & 5.0428 & 50 & 75 \\
3 & 6.3035 & 45 & 80 \\
\hline
\end{tabular}


concentration of oxalic acid at constant temperature $(280 \mathrm{~K})$ and voltage $(40 \mathrm{~V})$. The superlative pore arrangement is perceived at $40 \mathrm{~V}$ of anodization voltage when oxalic acid is used as the electrolyte. ${ }^{28}$ At anodization potential of $40 \mathrm{~V}$, lower concentration of electrolyte helps in the pore formation with a diameter of $96 \mathrm{~nm}$ and wall thickness of $50 \mathrm{~nm}$. An increase in the concentration of the electrolyte is directly proportional to the increase in the wall thickness of porous alumina. In the previous reports, the first anodized samples showed long ordered pore arrangement and high porosity. ${ }^{29}$ In this work, less ordered pore arrangement and moderate porous template are fabricated by decreasing the time of anodization. Figure 1 shows the FE-SEM image of sample number- 1 from table 1.

It is apparent from figure 1 that the pore formation is coarsely uniform and equally spaced at lower concentrations of oxalic acid. The pore diameter $(\mathrm{nm})$ of the first anodized samples increased linearly with the increase in the concentration of oxalic acid (figure 2). The relation between the pore diameter in $\mathrm{nm}$ and oxalic acid concentration is given as,

$$
\text { Pore diameter }\left(D_{p}\right)=14.387 \times-16.529
$$

where $\mathrm{x}$ is concentration of oxalic acid in the range of 2.5-5 wt \%. Cell diameter is the dimension of pore diameter including the wall thickness. The cell diameter is constant around $80-120 \mathrm{~nm}$, while the porosity increased from $10 \%$ to $30 \%$ with the increase in the concentration of oxalic acid. Above $4.4 \mathrm{wt} \%$ of oxalic acid, the porosity and pore diameter started decreasing. In this paper, $3.78 \mathrm{wt} \%$ concentration of oxalic acid was chosen due to the self-ordered regime behaviour of the aluminium layer. Porosity $(\mathrm{P})$ is calculated using the formula, ${ }^{30}$

$$
\mathrm{P}=\left(\frac{\pi}{2 \sqrt{3}}\right)\left(\frac{D_{p}}{D_{c}}\right)^{2}
$$

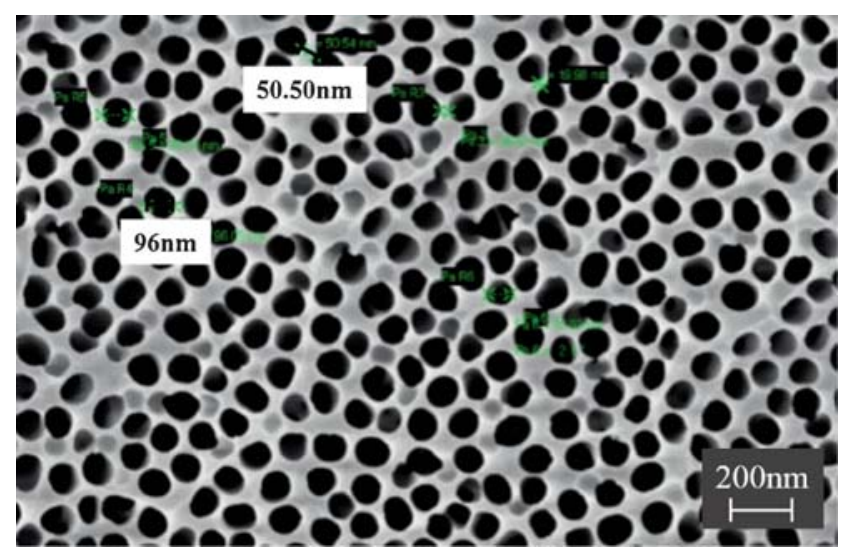

Figure 1. SEM morphological image of sample no.1 from table 1 .
$D_{\mathrm{p}}$ and $D_{\mathrm{c}}$ are pore diameter and interpore distance respectively.

After first anodization, the oxide layer was removed using the mixture of $\mathrm{H}_{3} \mathrm{PO}_{4}$ and $\mathrm{H}_{2} \mathrm{CrO}_{4}$, leaving behind the weak spots for second anodization.

\subsection{Step two with Orthophosphoric acid}

Anodization carried out with orthophosphoric acid at room temperature resulted in $120 \mathrm{~nm}$ pore diameter and $40 \mathrm{~nm}$ wall thickness with no-self ordering. This result agrees with the findings of Masuda et al., ${ }^{3}$ where the anodization was processed at $150 \mathrm{~V}$. The irregularities were observed because of the heat generated on the surface of the electrolyte due to high anodization voltage. To overcome the irregularities, the experiments were conducted on pre-anodized samples, which resulted in improved pore arrangement and physical properties of the porous alumina. Table 2 shows the variations in pore diameter and wall thickness in relation to the time of anodization. Inter-pore distance and pore diameter of the second anodized samples were calculated from FE-SEM top-view images for different anodization timing.

In the second anodization, the time of anodization was varied from $1 \mathrm{~min}$ to $3 \mathrm{~min}$ (figure 3 ). Figure 4 shows the relationship between anodization time and cell or pore diameter along with porosity. Even though the cell and pore diameter increased linearly, the porosity

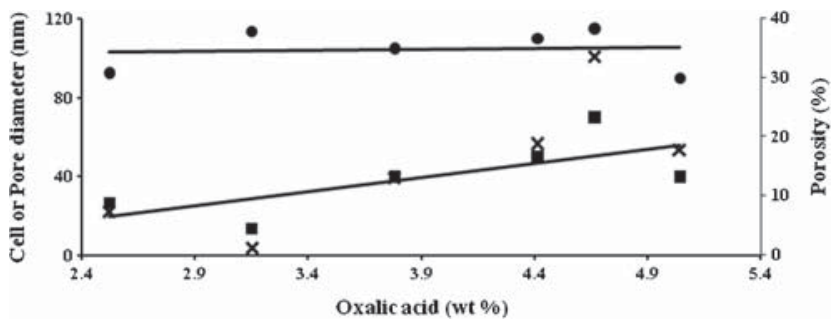

Figure 2. Relationship between concentration of oxalic acid in $\mathrm{wt} \%$, cell diameter in $\mathrm{nm}(\bullet)$, pore diameter in $\mathrm{nm}$ (घ) and porosity in $\%(x)$.

Table 2. Re-anodization at constant temperature (293 K) and voltage $(150 \mathrm{~V})$ by varying the time of anodization.

\begin{tabular}{lccc}
\hline $\begin{array}{l}\text { Sample } \\
\text { No. }\end{array}$ & $\begin{array}{c}\text { Time } \\
(\mathrm{min})\end{array}$ & $\begin{array}{c}\text { Pore diameter } \\
(\mathrm{nm})\end{array}$ & $\begin{array}{c}\text { Wall thickness } \\
(\mathrm{nm})\end{array}$ \\
\hline 1 & 2.2 & 130 & 128 \\
2 & 2.5 & 150 & 100 \\
3 & 3.1 & 180 & 130 \\
4 & 3.16 & 200 & 130 \\
\hline
\end{tabular}




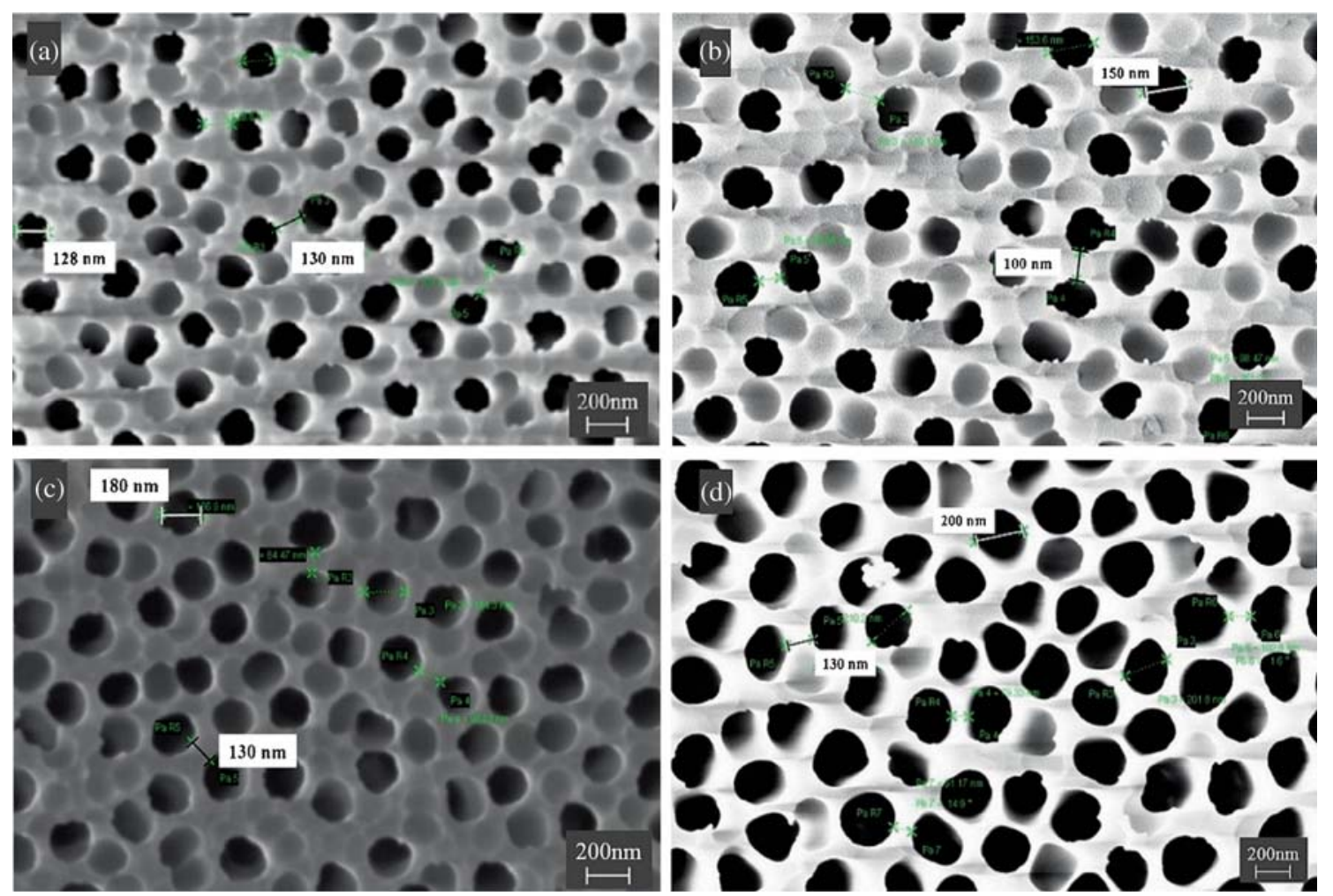

Figure 3. FE-SEM top-view micrographs for various times of re-anodization: $2.2 \mathrm{~min}$ (a), $2.5 \mathrm{~min}$ (b), $3.1 \mathrm{~min}(\mathbf{c})$ and $3.16 \mathrm{~min}(\mathbf{d})$ carried out in $1 \%$ phosphoric acid. The first anodization was carried out in $0.3 \mathrm{M}$ oxalic acid electrolyte at $280 \mathrm{~K}$ and $40 \mathrm{~V}$.

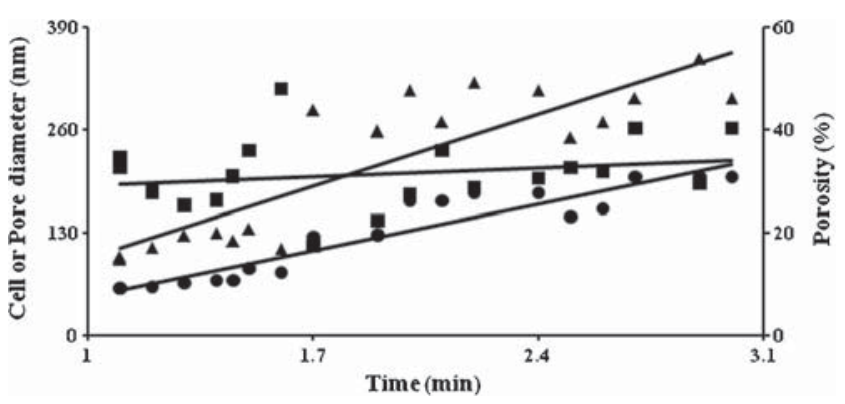

Figure 4. Relationship between anodization time in minutes with cell diameter in $\mathrm{nm}(\boldsymbol{\Delta})$, pore diameter in $\mathrm{nm}(\bullet)$ and porosity in $\%(\square)$.

is observed to be maximized $(47 \%)$ at $1.6 \mathrm{~min}$. Above 1.6 min of anodization time, the porosity was verified to be saturated around $30 \%$. The pore diameter obtained increased with increase in time from $130-200 \mathrm{~nm}$. The irregularity of pore arrangement in the first anodization had no effect in the pore formation by second anodization. The current density in second anodization was very small, so the $\mathrm{Al}^{3+}$ dissolution is from the bottom of the pores. By increasing the anodization time, the height of the oxide layer was increased and the regularity of long pore channel was not affected. ${ }^{31}$

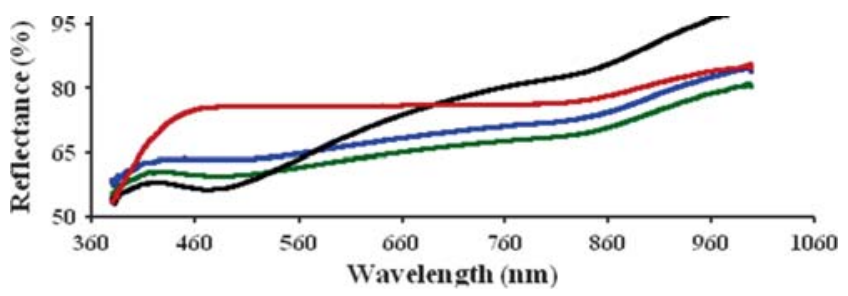

Figure 5. Reflection spectra of the re-anodized porous alumina formed using $1 \%$ phosphoric acid for different pore diameter: cell diameter in $\mathrm{nm}$ 139:176 (black), 114:153 (green), 84:156 (blue) and 56:67 (red).

\subsection{Reflectance of anodized aluminium}

Reflection spectra of re-anodized porous alumina of different pore size (d) and wall thickness (t) are shown in figure 5. According to the previous reports, the transmittance increases as the anodised membrane is heated to $973 \mathrm{~K} .{ }^{32}$ From figure 5, it can be identified that when the pore diameter is $56 \mathrm{~nm}$ the reflectance average is $76 \%$ and as the pore diameter increases to 84,114 and $139 \mathrm{~nm}$, the reflectance averages are 69, 66, and $74 \%$, respectively. In the sample with pore diameter $139 \mathrm{~nm}$ and wall thickness $176 \mathrm{~nm}$, the reflectance is high (80\%) at wavelength $730 \mathrm{~nm}$ and it drops down to $56 \%$ at $480 \mathrm{~nm}$. There is a noticeable difference in 
the absorption of the solar spectrum as the porosity increases. The surface area of the alumina substrate also increases along with the increase in the porosity, making a way for further interaction between the photons in the solar spectrum and the $\mathrm{Al}_{2} \mathrm{O}_{3}$ which leads to higher absorption factor due to total internal reflection.

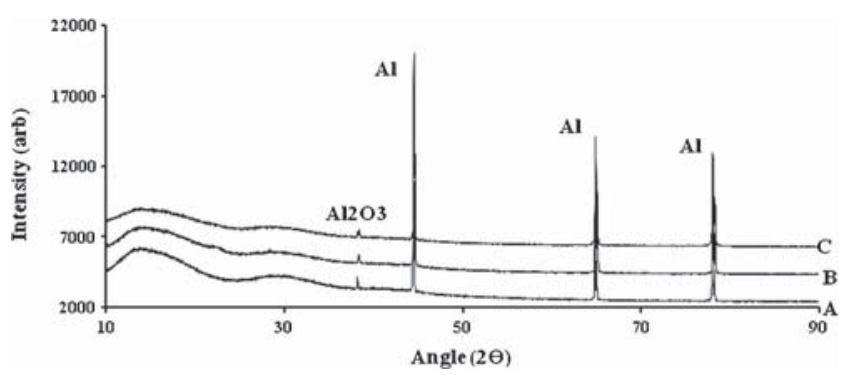

Figure 6. XRD pattern of (A) aluminum, (B) first anodized alumina and $(\mathrm{C})$ second anodized alumina.

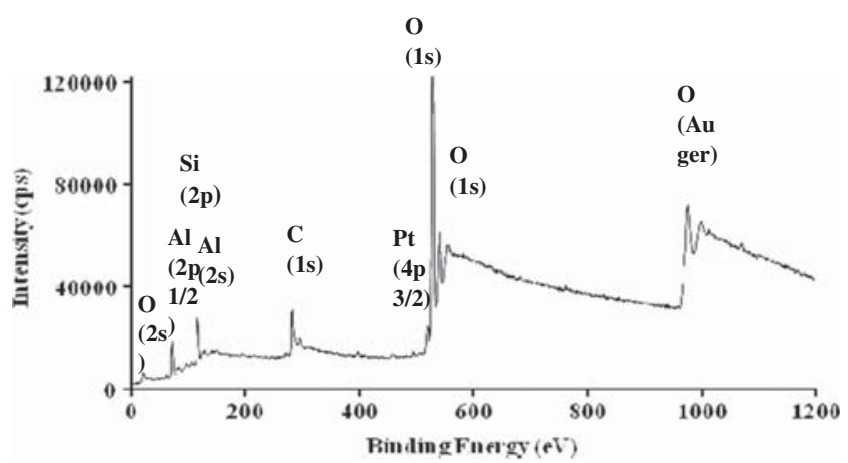

Figure 7. X-ray photoelectron spectrum of two-step anodized alumina after the oxide growth for $3 \mathrm{~min}$ in phosphoric acid.

\section{$3.4 \quad X$-Ray diffraction (XRD) analysis}

Figure 6 shows the X-ray diffraction pattern of aluminium and anodized aluminium samples. From the diffraction pattern, it is noticed that the $\mathrm{Al}$ and $\mathrm{Al}_{2} \mathrm{O}_{3}$ phases are present in the anodized sample. This infers that after anodization, the porous $\mathrm{Al}_{2} \mathrm{O}_{3}$ layer was formed on the substrate. X'pert high score plus (version 2.0) is used to identify the peaks. In figure 6A, the aluminium peaks that appeared at $2 \theta=44.48,64.88$ and 78.03 (JCPDS file no. 01-089-2837) confirmed the cubic structure of $\mathrm{Al}$ substrate. After first anodization, the tetragonal $\mathrm{Al}_{2} \mathrm{O}_{3}$ peaks were observed at $2 \theta=38.29$ (JCPDS file no. 04-016-7505) as shown in figure 6B. The peaks of the re-anodized sample which occurred at $2 \theta=38.32$ (JCPDS file no. 04-016-7505) indicates the tetragonal structure of $\mathrm{Al}_{2} \mathrm{O}_{3}$ as shown in figure $6 \mathrm{C}$.

\subsection{X-ray photo electron spectroscopic (XPS) analysis}

XPS spectra of the re-anodized aluminium oxide layer are shown in figure 7 . The intensity peaks of the anodized aluminium correspond with the general spectra of $\mathrm{Al}_{2} \mathrm{O}_{3} .{ }^{33}$ The impurity peaks identified with Platinium $(\mathrm{Pt})$ and Silicon $(\mathrm{Si})$ originated from the electrode and the substrate used when anodization was carried out. The sample showed traces of $\mathrm{Pt}$ and $\mathrm{Si}$ on the surface, apart from aluminium $(\mathrm{Al})$, oxygen $(\mathrm{O})$ and carbon $(\mathrm{C})$. Figure $8 \mathrm{a}$ shows the high-resolution $\mathrm{Al} 2 \mathrm{p}$ spectra of the re-anodized aluminium sample. The binding energy of the $\mathrm{Al} 2 \mathrm{p}$ is located at $73.1 \mathrm{eV}$ which matches the orbital value of $\mathrm{Al} 2 \mathrm{p}_{3 / 2}$, for $\mathrm{O} 1 \mathrm{~s}$ at $530.9 \mathrm{eV}$ and $\mathrm{C} 1 \mathrm{~s}$ at $283.6 \mathrm{eV}$ as shown in figure $8 \mathrm{a}, \mathrm{b}$ and $\mathrm{c}$, respectively. From this analysis, it is verified that the AAO film
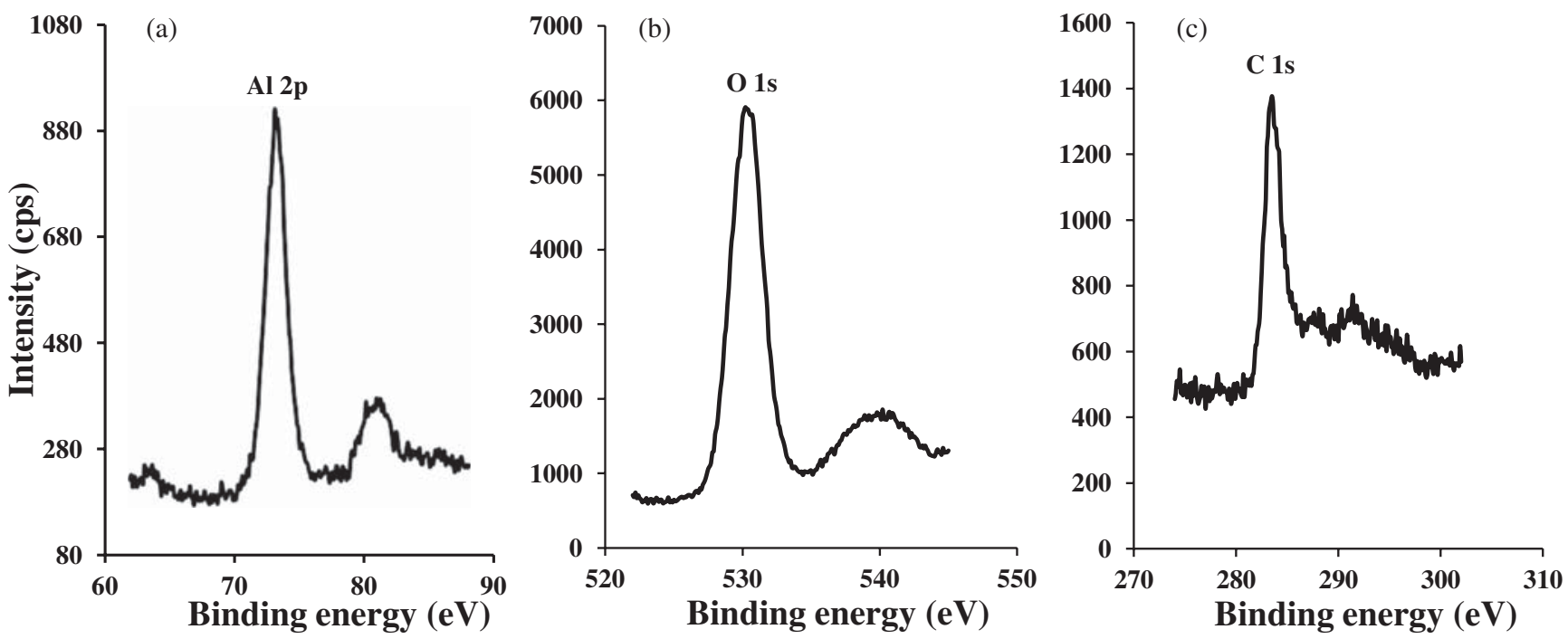

Figure 8. X-ray photoelectron spectra of two-step anodized alumina after the growth of oxide layer: $\mathrm{Al} 2 \mathrm{p}$ (a), $\mathrm{O}$ 1s (b) and $\mathrm{C} 1 \mathrm{~s}(\mathbf{c})$. 
fabricated by two-step anodization does not contain any alloying elements.

\section{Conclusions}

A fast anodization process that takes less than $15 \mathrm{~min}$ is described. It is a two-step anodization process and the pore formation was found to be dependent on the temperature of the electrolyte. Varying the time of anodization process, the pore density can be controlled. Based on the two-step anodization process, oval-shaped pores were formed with $180 \mathrm{~nm}$ pore diameter and $130 \mathrm{~nm}$ wall thickness. The ratio of light absorption by anodized samples with different pore sizes increased with an increase in surface area. Therefore, while using anodized alumina in thin-film solar cells, it is anticipated to be beneficial for enhanced light trapping. XRD analysis showed the existence of $\mathrm{Al}_{2} \mathrm{O}_{3}$ peaks after anodization. And XPS data of anodized Al showed traces of $\mathrm{Al}, \mathrm{O}, \mathrm{C}, \mathrm{Si}$ and $\mathrm{Pt}$ along with their orbital values. The presented method of ultra-fast anodization can be tuned for further control over the pore size and its arrangement.

\section{References}

1. Routkevitch D, Bigioni T, Martin M and Jing M X 1996 J. Phys. Chem. 10014037

2. O'Sullivan J P and Wood G C 1970 Proc. Roy. Soc. Lond. A 317511

3. Masuda H and Fukuda K 1995 Science 2681466

4. Diggle J W, Thomas C D and Goulding C W 1969 Chem. Rev. 69365

5. Nielsch K, Choi J, Schwirn K, Wehrspohn R B and Gösele U 2002 Nano Lett. 2677

6. Ono S, Saito M and Asoh H 2005 Electrochem. Micro Nano Tech. 51827

7. Kikuchi T, Yamamoto T and Suzuki R O 2013 Appl. Surf. Sci. 284907

8. Sulka G D and Stepniowski W J 2009 Electrochim. Acta 543683

9. Lu C and Zhi C 2011 Encyclopedia of Nanoscience and Nanotechnology 11235
10. Poinern G E J P, Ali N and Fawcett D 2011 Materials 4 487

11. Ono S and Masuko N 2003 Surf. Coat. Tech. 169-170 139

12. Sulka G D, Stroobants S, Moshchalkov V, Borghs G and Celis J P 2002 J. Electrochem. Soc. 149D 97

13. Buijnsters J G, Rui Z, Natalia T and Celis J P 2013 ACS Appl. Mater. Interfaces 53224

14. Coz F L, Arurault L and Datas L 2010 Mater. Charact. 61283

15. Nguyen T N, Kim D, Jeong D-Y, Kim M-W and Uk Kim J 2012 Electrochim. Acta 83288

16. Masuda H, Yamada H, Satoh M, Asoh H, Nakao M and Tamamura T 1997 Appl. Phys. Lett. 712770

17. Jessensky O, Müller F and Gösele U 1998 J. Electrochem. Soc. 1453735

18. Chung C K, Liao M W, Chang H C and Lee C T 2011 Thin Solid Films $\mathbf{5 2 0} 1554$

19. Sulka G D, Stroobants S, Moshchalkov V V, Borghs G and Celis J P 2004 J. Electrochem. Soc. 151B 260

20. Lee W, Ji R, Gösele U and Nielsch K 2006 Nature Mater. 5741

21. Ono S, Saito M and Asoh H 2005 Electrochim. Acta 51 827

22. Debuyck F, Moors M and Peteghem A P V 1993 Mater. Chem. Phys. 36146

23. Li A P, Müller F, Birner A, Nielsch K and Gösele U 1998 J. Appl. Phys. 846023

24. Bae E J, Choi W B, Jeong K S, Chu J U, Park G S, Song S and Yoo I K 2002 Adv. Mater. 14277

25. Liu J, Liu S, Zhou H, Xie C, Huang Z, Fu C and Kuang Y 2014 Thin Solid Films 55275

26. Sulka G D and Stépniowski W J 2009 Electrochim. Acta 543683

27. Sousa C T, Leitao D C, Proenca M P, Ventura J, Pereira A M and Araujo J P 2014 Appl. Phys. Rev. 1031102

28. Vrublevsky I A, Chernyakova K V, Ispas A, Bund A and Zavadski S 2014 Thin Solid Films 556230

29. Crist B V 1999 In Handbooks of Monochromatic XPS Spectra 2 (California: XPS International LLC)

30. Surawathanawises K and Cheng X 2014 Electrochim. Acta 117498

31. Li F, Zhang L and Metzger R M 1998 Chem. Mater. 10 2470

32. Zaraska L, Stepniowski W J, Sulka G D, Ciepiela E and Jaskuła M 2013 Appl. Phys. A 114571

33. Li Y, Zheng M, Ma L and Shen W 2006 Nanotechnology 175101 